\title{
Identification of Synthetic Food Colours in Selected Confectioneries and Beverages in Jaffna District, Sri Lanka
}

\author{
P. G. T. Dilrukshi $\mathbb{D}^{1}{ }^{1}$ Helani Munasinghe $\mathbb{D}^{1},{ }^{1}$ A. Buddhika G. Silva $\mathbb{D},{ }^{2}$ \\ and P. G. S. M. De Silva $\mathbb{i D}^{2}$ \\ ${ }^{1}$ Department of Botany, University of Sri Jayewardenepura, Nugegoda, Sri Lanka \\ ${ }^{2}$ Department of Nutrition, Medical Research Institute, Colombo-08, Sri Lanka
}

Correspondence should be addressed to A. Buddhika G. Silva; buddhika-gayani@mri.gov.lk

Received 13 May 2019; Accepted 7 September 2019; Published 1 October 2019

Academic Editor: Susana Fiszman

Copyright (c) 2019 P. G. T. Dilrukshi et al. This is an open access article distributed under the Creative Commons Attribution License, which permits unrestricted use, distribution, and reproduction in any medium, provided the original work is properly cited.

\begin{abstract}
Colour is a key component to enhance the ultimate appetizing value and consumer acceptance towards foods and beverages. Synthetic food colours have been increasingly used than natural food colours by food manufacturers to attain certain properties such as low cost, improved appearance, high colour intensity, more colour stability, and uniformity. Varied foods and beverages available in the market may contain some nonpermitted synthetic colours and overuse of permitted synthetic colours. This may lead to severe health problems such as mutations, cancers, reduced haemoglobin concentrations, and allergic reactions. According to the Food Act, 2011 (No. 26 of 1980), Sri Lanka, only nine synthetic food colours are permitted and the colour concentration cannot exceed $100 \mathrm{ppm}$ as a single component or in combination. This study aims to identify the synthetic food colours in confectioneries and beverages available in Jaffna district, Sri Lanka. Randomly collected 110 samples from eleven Medical Officers Of Health areas in Jaffna district were analyzed by using thin layer chromatography and UV-visible spectrophotometry. According to the results, $100 \%$ beverages and $85 \%$ confectioneries contained permitted synthetic food colours. Out of all, $7 \%$ of the confectioneries did not contain any synthetic food colour and $8 \%$ of the confectioneries contained nonpermitted colours which do not comply with any of the permitted synthetic food colours. Tartrazine (E102) (41\%) was the most used synthetic food colour in both confectioneries and beverages. Moreover, $60 \%$ of the beverages violated the label requirement without including proper colour ingredients. The study concluded that there is a high tendency to use synthetic food colours in confectioneries and beverages and some confectioneries contain unidentified colours including a textile dye. Therefore, the implementation of regulations and awareness programs of food colours for consumers and food manufacturers are highly recommended.
\end{abstract}

\section{Introduction}

Food manufacturers commonly use food additives in different foods and beverages to increase taste, appearance, and flavour [1-4]. Since the visual aspect plays an important role in the selection of food products by modern consumers, colour is a key constituent of food and beverages $[5,6]$. In recent years, many synthetic food colours have been increasingly used as additives to substitute natural colours, to achieve certain properties such as improved appearance, high colour intensity, more colour stability, and colour uniformity [7-10]. Compared to natural colours, synthetic food colours have several economically important traits such as low cost, resistance to light, oxygen, and $\mathrm{pH}$ changes, and high colour stability [1]. It can be used without further processing and does not degrade during food processing [11].

Synthetic food colours are chemicals which originate from coal tar derivatives, and most of them contain an azo group [12]. These colours can be divided into two categories as permitted and nonpermitted [13]. Synthetic food colours are widely used in many foods such as bakery products, confectioneries, jellies, and beverages available in the market. Varied foods and beverages available in the market may contain some nonpermitted synthetic colours as well as the overuse of permitted synthetic colours. Numerous 
studies have confirmed that the synthetic food colours are a major source of food intoxication [14] and lead to severe health problems such as low haemoglobin concentration, allergic reactions, mutations, cancers, irritability, restlessness, sleeping disturbances, effects on the liver, kidney, and intestine, hyperactive effects on children, ear infections, asthma, and eczemas [6, 15-19]. Indiscriminate use of permitted synthetic colours is also not safe $[6,20]$.

The use of nonpermitted colours and indiscriminate use of permitted colours are known to cause adverse health effects in experimental animals [21-24] and in humans [25-27]. The aim of the labelling of food items is to stimulate the consumer's interest by providing information on nutritional attributes and different additive contents of the product for the consumer to make informed decisions [28]. The Ministry of Health, Sri Lanka, made regulations to restrict adulteration of food with nonpermitted synthetic colours under Extraordinary Gazette 2011, Food Act No. 26 of 1980. It permits only nine synthetic food colours [29], and colour concentration cannot exceed $100 \mathrm{ppm}$ as a single component or in combination [30]. The permitted colours are Carmoisine/Azorubine (E 122), Ponceau 4R (E 124), Erythrosine (E 127), Allura Red (E 129), Tartrazine (E 102), Sunset yellow FCF (E110), Indigotine/Indigo carmine (E132), Brilliant Blue FCF (E 133), and Fast Green FCF (E 143) [29]. Moreover, food additives should be prescribed by its name or INS number [31]. The present study involves the identification of synthetic food colours in randomly collected confectioneries and beverages from Jaffna district, Sri Lanka, by using thin layer chromatographic (TLC) method and UV-visible spectrophotometric methods.

\section{Materials and Methods}

2.1. Sample Collection. A total of 110 (100 confectionaries and 10 beverages) samples were randomly collected from retail shops in eleven Medical Officer of Health $(\mathrm{MOH})$ areas in Jaffna district.

\subsection{Chemicals and Instruments}

2.2.1. Permitted Synthetic Colour Standards. The permitted colours are Carmoisine/Azorubine (E 122), Ponceau 4R (E 124), Erythrosine (E 127), Allura Red (E 129), Tartrazine (E 102), Sunset yellow FCF (E110), Indigotine/Indigo Carmine (E132), Brilliant Blue FCF (E 133), and Fast Green FCF (E 143).

2.2.2. Nonpermitted Colour Standards. The nonpermitted colours are Fast red, Rhodamine B, Metanil yellow, Bromocresol purple, Green S, Sudan 1, Sudan 2, Sudan 3 and Sudan 4.

2.2.3. Chemicals. Petroleum ether, acetic acid, ammonia, butanol, n-propanol, methanol, and ethanol were purchased from Sigma (Sigma-Aldrich Co., St. Louis, MO, USA).
2.2.4. Instruments. The instruments used were a Himac SCT $5 \mathrm{~B}$ centrifuge and GENESYS 10S UV-VIS spectrophotometer.

2.3. Sample Preparation. The confectionery sample types used were categorized as boondi, sweets, murukku, nice papadam, bird-candy, laddu, pallimidai, muscut, honey murukku, sweet toffee, pori balls, marshmellows, instant jelly, and other sweets. Beverages were categorized as cordials and nectar.

2.3.1. Preliminary Treatments. In the case of beverages, liquid samples were directly used for colour extraction [4].

In the case of confectionaries, $5.0 \mathrm{~g}$ of a ground sample was weighed and oil was totally removed using petroleum ether. Then, $10.0 \mathrm{ml}$ of $2 \%$ ammonia in $70 \%$ alcohol was added to the oil-removed sample, and the mixture was warmed in a water bath for 2-3 minutes for starch to settle down. The resulting coloured liquid was centrifuged at 30,000 rpm for 15 minutes. The separated liquid was evaporated on the water bath.

2.4. Colour Extraction. Each pretreated sample was acidified by $2.0 \mathrm{ml}$ of $2 \mathrm{M}$ glacial acetic acid, an equal amount of distilled water, and $5.0 \mathrm{~cm}$ length conditioned pure sheep wool thread. This was kept in a water bath for 1 hour for the colour to be adsorbed onto the wool. The wool thread was then removed from the solution and washed with running tap water. It was resoaked in $2.0 \mathrm{ml}$ of $2 \mathrm{M}$ ammonia solution with an equal amount of distilled water and kept in a water bath until the wool thread was decolorized. The wool thread was removed, and the solution was concentrated by evaporation in a water bath $[8,32]$.

\subsection{Identification of Extracted Colours}

2.5.1. Chromatographic Analysis. Extracted colours were identified by thin layer chromatography. Extracted colour samples and colour standards were dissolved in a few drops of distilled water with one drop of ethanol. Mobile phases were prepared using distilled water: butanol:glacial acetic acid $(6: 10: 5)$ and propanol:ammonia $(4: 1)$ for colour identification [12].

2.5.2. Retention Factor ( $R f)$. In chromatography, retention factor (Rf) is the fraction of the sample in the mobile phase at equilibrium $[7,8,12]$. It was calculated after recording the separated colour spots. The position of each spot was taken from its centre. It was calculated according to the following equation:

$R_{\mathrm{f}}=\frac{\text { distance of the colour spot travelled from the baseline }}{\text { distance of the solvent travelled from the baseline }}$.

The $R_{\mathrm{f}}$ values of samples and standards were compared. 


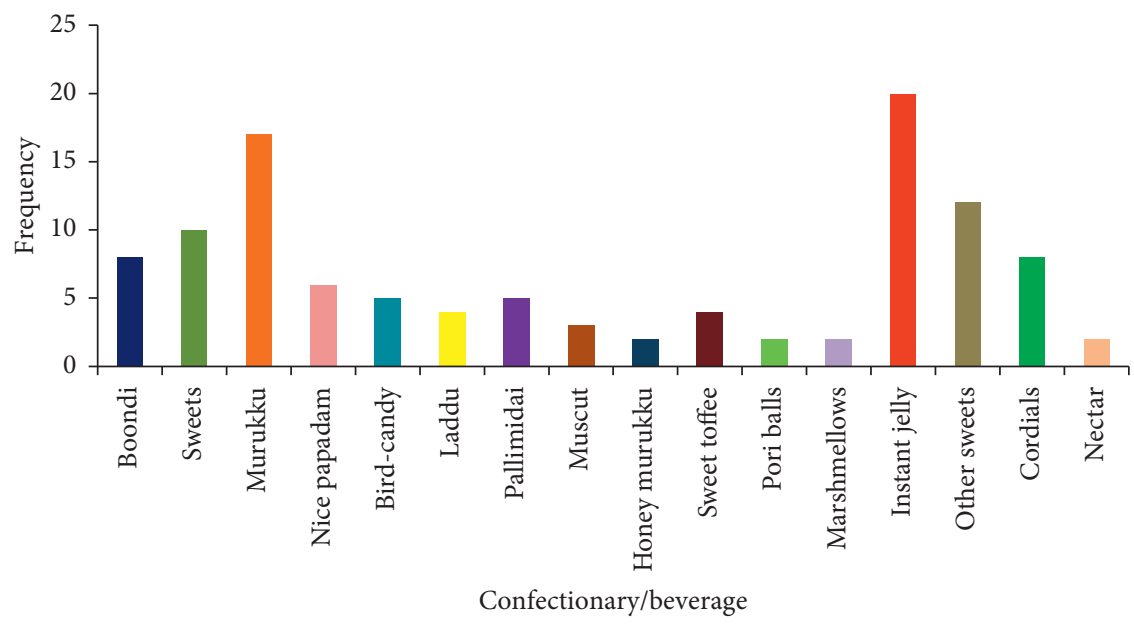

FIGURE 1: Frequency of different categories of confectioneries and beverages collected in Jaffna district.

2.6. UV-Visible Spectrophotometric Analysis. Unidentified colours were confirmed by using a UV-visible spectrophotometer. In this study, all synthetic permitted food colour standards in Sri Lanka were used. A colour standard of $0.0001 \mathrm{M}$ was prepared using distilled water and one drop of methanol. The unrecognized colour spot in TLC silica plate was scratched and dissolved in 5 drops of distilled water and 2 drops of methanol. The upper liquid layer was separated, and the $\lambda_{\max }\left(\lambda_{\max }\right.$ or lambda max refers to the wavelength of the absorption spectrum where the absorbance is maximum) was measured for each colour standard and samples within the wavelength range of $280 \mathrm{~nm}-800 \mathrm{~nm}$ using a UV-visible spectrophotometer. The spectra and $\lambda_{\max }$ value of samples and standards were compared with each other. The reproducibility test was performed after 14 days of TLC analysis.

\section{Results and Discussion}

The study was conducted to identify the synthetic food colours used for beverages and confectionaries in Jaffna district. A total of 110 samples (100 confectionaries and 10 beverages) were randomly collected from retail shops in $\mathrm{MOH}$ areas in Jaffna district, Sri Lanka. Figure 1 shows the frequency distribution of confectioneries and beverages randomly collected from Jaffna district.

Figure 2 shows the colour distribution of confectionaries by TLC.

Figure 2 reveals that among confectioneries, $8 \%$ contain nonpermitted colours which did not comply with permitted synthetic food colours accepted by Food Act in Sri Lanka. The results show that $93 \%$ of confectionaries contained synthetic colours. Furthermore, all beverages contained only permitted synthetic food colours.

Saleem et al. also identified that $11 \%$ of food samples and $4 \%$ of beverages contained nonpermitted colours in Karachi city, Pakistan, and they were unfit for human consumption [14]. Yadav et al. identified nonpermitted Metanil yellow and malachite green in cake and ice cream samples in local areas in Allahabad, India [2]. Furthermore, Rezaei et al. identified

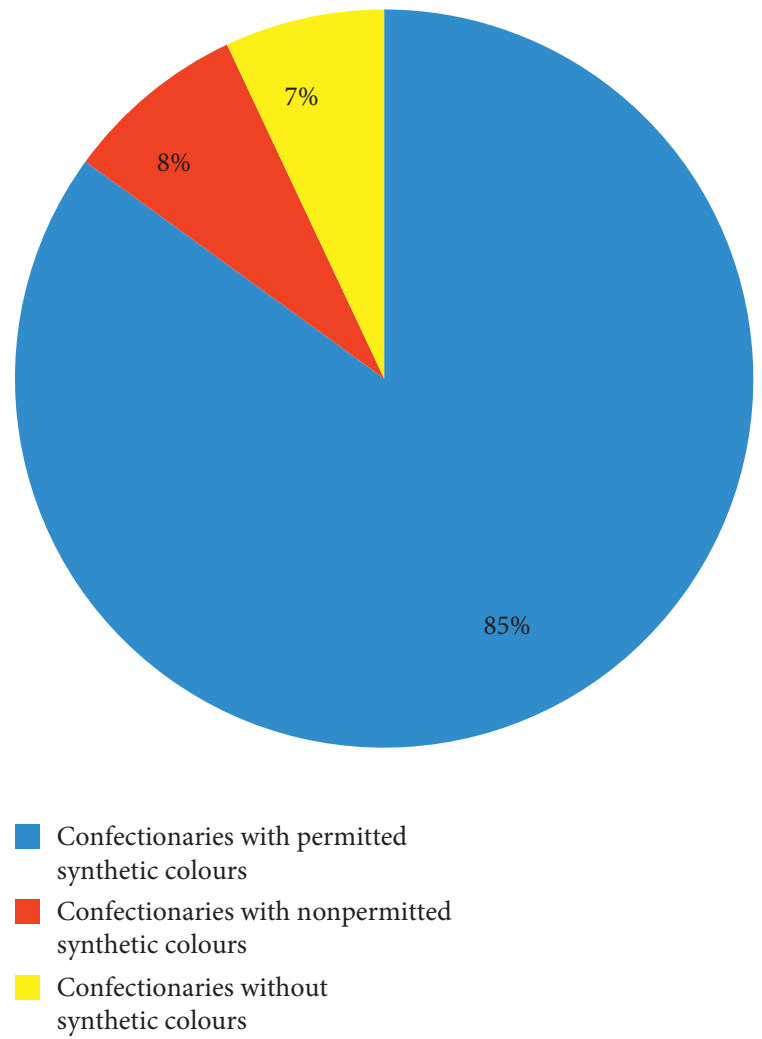

FIgURE 2: Colour distribution of the confectionaries collected from Jaffna district as percentage.

that among 70 food items in Arak, Iran, 80\% contained artificial colour additives that are banned to be used in foods by the National Iranian Standards and 20\% did not contain any artificial food colour additive [7]. Farzianpour et al. revealed that $6.52 \%$ of the food items among analyzed pastry, poolak, and rock candy in Shahr-e-kord City, Iran, contained forbidden artificial food colours [8]. Ashfaq and Masud revealed that among 73 samples of sweetmeats and confectioneries in Rawalpindi Cantt., Pakistan, 46.57\% contained nonpermitted colours [6]. Therefore, the current study creates a dire need to assure food safety and 
quality to ensure the use of food colours in a controlled range.

Furthermore, Figure 3 indicates that Tartrazine-E102 (41\%) was the most used synthetic food colour among both confectioneries and beverages and the other permitted food colours were Sunset yellow FCF-E110 (22\%), Brilliant Blue-E133 (15\%), Erythrosine-E129 (10\%), Carmoisine-E122 (8\%), and Ponceau 4R-E124 (4\%). Allura Red (E129), Indigo carmine (E132), and Fast Green FCF (E143) colours were not found among the analyzed samples.

In recent years, due to toxicological impacts, most of the countries now have a very short list of permitted synthetic colour additives. Different countries permit different synthetic food colours. Even though Sri Lanka permits only nine synthetic food colours as edible, Pakistan permits eighteen synthetic food colours, USA permits seven food colours, Iran and Australia permit thirteen each, and in the European Union (EU), sixteen synthetic food colours are permitted as edible $[14,33]$. The maximum limit of permissible colours to be added in any food shall be $0.1 \mathrm{~g} / \mathrm{kg}$ of food as consumed in all countries [14].

According to Rao et al., the intake of Tartrazine and Sunset yellow was observed to be higher during festivals in Hyderabad, India, among sweetmeats, beverages, and fast food. It is because of the popular belief that yellow is an auspicious colour in most of Asia and is also known to be a colour of royalty [5]. Ashfaq and Masud 2002, also observed that Tartrazine is the frequently used synthetic colour in almost all kinds of sugar confectioneries in Rawalpindi Cantt., Pakistan [6]. Studies performed by Jonnalagadda et al. revealed that among ready-to-eat foods in Hyderabad, India, 54\% contained Tartrazine, 31\% had sunset yellow, 19\% had brilliant blue FCF, 10\% had carmoisine, $8 \%$ had Ponceau $4 \mathrm{R}$, and $3 \%$ had erythrosine [23]. Saleem et al. observed that Tartrazine and Sunset yellow were the most common permitted colours used in various food products such as confectioneries, ice balls, chewing gums, bakery products, and beverages in Karachi City, Pakistan [14]. Choi also observed that Tartrazine (23.3\%) was the most commonly used artificial colourant among the analyzed samples such as bakery products, snacks, candies, chocolates, chewing gums, jam, ice cream, drinks, salted vegetables, and alcoholic beverages in Korea [33]. Therefore, the current results are similar to the results of the previous studies in other countries.

Even though Tartrazine is an approved azo dye present in many food products; its sensitivity is most frequently manifested by urticaria and asthma; the mechanism of sensitivity is obscure and is called pseudoallergy [14]. Furthermore, it is associated with irritability, restlessness, and sleep disturbance in hyperactive children aged between two and fourteen years [18]. Moreover, Sunset yellow and Ponceau $4 \mathrm{R}$ have also been implicated to have adverse reactions in patients with chronic urticaria [34], and erythrosine has estrogen-like growth stimulatory properties which may be genotoxic and could be a significant risk factor in human breast cancer [35]. Therefore, it is essential

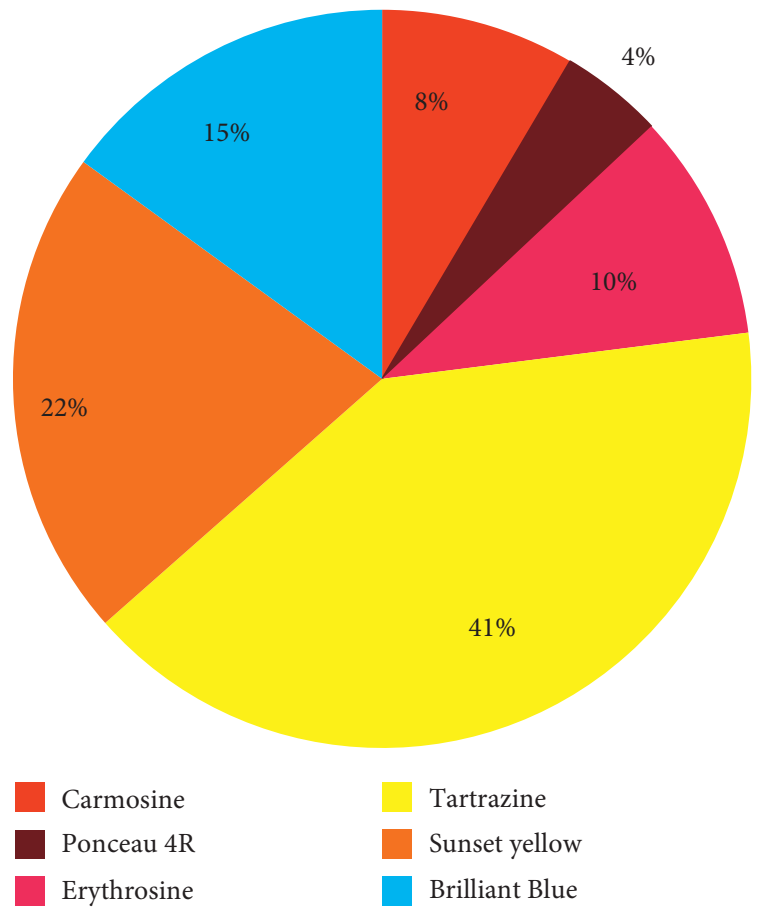

Figure 3: Distribution of food colours in confectionaries and beverages as percentage.

to make internationally accepted strategies to implement food safety and quality to control the usage of Tartrazine, sunset yellow, erythrosine, and Ponceau 4R. Moreover, consumption of coloured food items can also be controlled by making the society aware of the hazardous effects of synthetic food colours.

According to Table 1, all unidentified nonpermitted colours were found in instant red jelly samples from four $\mathrm{MOH}$ areas in Jaffna district. These jelly samples were labelled under two different brand names and manufactured in Western Province, Sri Lanka, even though they were sold in Jaffna district. One of those brands commercially available in Colombo district, Sri Lanka, also contained the same nonpermitted colour. Table 1 indicates that the $R_{\mathrm{f}}$ value and $\lambda_{\max }$ of nonpermitted colours are nearly equal to 0.22 and $430 \mathrm{~nm}$ respectively. Nonpermitted colour spots appeared as yellow in "butan-1-ol: water : glacial acetic acid $(10: 6: 5)$ " and turned to red after 2 weeks when it was fully dried. The colour spots were changed to purple at $\mathrm{pH} 14$.

Table 2 shows the $R_{\mathrm{f}}$ values and $\lambda_{\max }$ of all red and yellow permitted synthetic colour standards and some nonpermitted red and yellow synthetic colour standards. Therefore, the $R_{\mathrm{f}}$ values of unidentified nonpermitted synthetic colours do not match with any of the above permitted and nonpermitted synthetic colour standards.

Figures 4 and 5 show the TLC analysis and spectrophotometric analysis of jelly (J90) sample containing nonpermitted colour.

Figure 5 shows that $\lambda_{\max }$ of nonpermitted colour found in the $J 90$ jelly sample was $430 \mathrm{~nm}$. Consequently, a nonpermitted colour found in red instant jelly samples J91, J92, 
TABLE 1: TLC and spectrophotometric analysis of nonpermitted dye in "instant red jelly" samples.

\begin{tabular}{lcc}
\hline Sample number & $R_{\mathrm{f}}$ value & $\lambda_{\max }$ value/nm \\
\hline Brand 1-J90 & 0.22 & 430 \\
Brand 1-J91 & 0.22 & 430 \\
Brand 1-J92 & 0.23 & 430 \\
Brand 1-J93 & 0.23 & 430.5 \\
Brand 2-J94 & 0.21 & 430 \\
Brand 2-J95 & 0.22 & 431 \\
Brand 2-J96 & 0.23 & 430 \\
Brand 2-J97 & 0.22 & 432 \\
\hline
\end{tabular}

TABLE 2: TLC and spectrophotometric analysis of some nonpermitted and all permitted synthetic red and yellow food colour standards.

\begin{tabular}{|c|c|c|c|c|c|}
\hline Colour standard & Colour & Permitted (P)/nonpermitted (NP) & $\Lambda \max / \mathrm{nm}$ & Solvent system & $R_{\mathrm{f}}$ value \\
\hline Carmoisine & Red & $\mathrm{P}$ & 516 & \multirow{6}{*}{$n$-Propanol: ammonia $=4: 1$} & 0.50 \\
\hline Ponceau 4R & Red & $\mathrm{P}$ & 508 & & 0.39 \\
\hline Erythrosine & Pink & $\mathrm{P}$ & 526 & & 0.77 \\
\hline Allura red & Red & $\mathrm{P}$ & 506 & & 0.46 \\
\hline Rhodamine B & Pink & NP & 553 & & 0.86 \\
\hline Fast red & Red & NP & 510 & & 0.55 \\
\hline Sunset yellow FCF & Orange & $\mathrm{P}$ & 482 & \multirow{4}{*}{ Butanol: water : glacial acetic acid $=10: 6: 5$} & 0.73 \\
\hline Tartrazine & Yellow & $\mathrm{P}$ & 426 & & 0.42 \\
\hline Bromocresol purple & Yellow & NP & 586 & & 0.91 \\
\hline Metanil yellow & Yellow & NP & 441 & & 0.85 \\
\hline
\end{tabular}

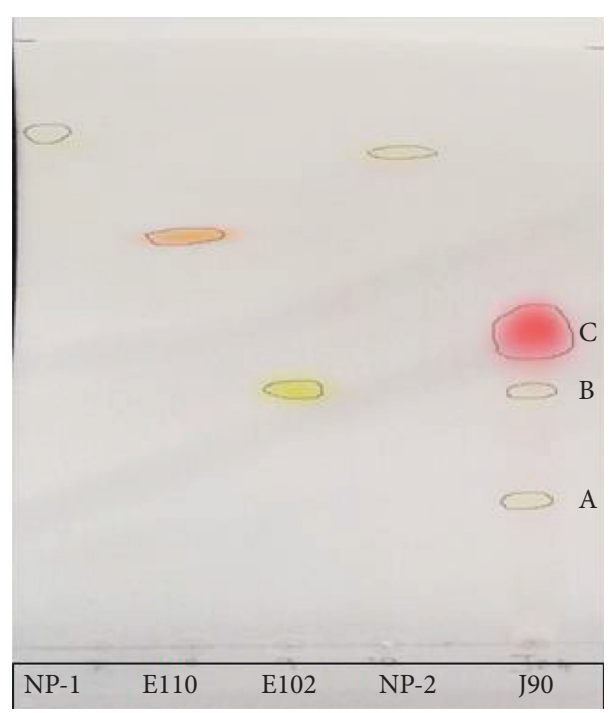

FIGURE 4: TLC analysis of J90 red instant jelly sample in the solvent system (butanol: water: glacial acetic acid = 10:6:5) which is used to identify yellow and orange synthetic colours. NP-1: nonpermitted Bromocresol purple; NP-2: nonpermitted Metanil yellow; E110: permitted standard Sunset yellow FCF; E102: permitted standard Tartrazine; A identified nonpermitted yellow colour spot; B identified Tartrazine colour spot; C identified red colour spot in jelly sample (Ponceau 4R-E 124).

J93, J94, J95, J96, and J97 contained similar spectra. In the TLC analysis, these nonpermitted colour spots appeared as yellow in the acidic medium (butan-1-ol: water: glacial acetic acid $=10: 6: 5)$ and turned to red after two weeks when it is fully dried. These nonpermitted colour spots were not detectable by paper chromatography analysis but appeared in thin layer chromatography analysis.

According to the literature, in acidic solutions, "alizarin" or "1,2-dihydroxy-9,10-anthraquinone" shows an absorption maximum of around $430 \mathrm{~nm}$ in methanol
[36, 37]. It is a stable organic pigment, mainly used for colouring textile [38]. It is also used as acid-base $\mathrm{pH}$ indicator in the chemical analysis [39] which indicates yellow $(\mathrm{pH} 5.5)$ to red $(\mathrm{pH} 6.8)$ and red $(\mathrm{pH} 10.1)$ to purple $(\mathrm{pH}$ 12.1) $[40,41]$. Therefore, alizarin appears yellow in the acidic medium, red in the neutral medium, and purple in the basic medium [42].

Based on the TLC (Figure 4), spectrophotometric results (Figure 5), and the literature, nonpermitted colour was identified as the textile dye "alizarin" or "1,2-dihydroxy9,10-anthraquinone." 


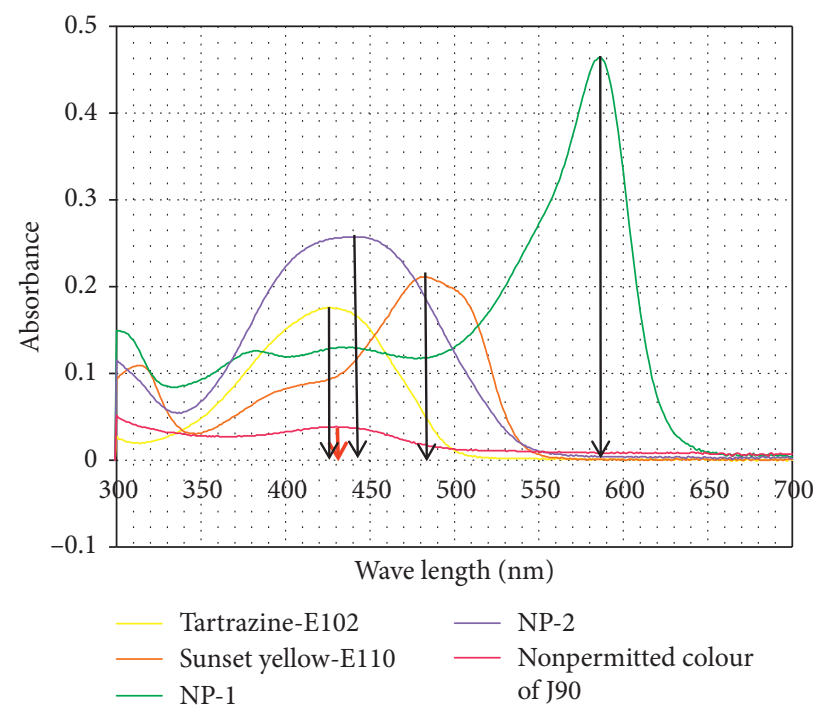

FIGURE 5: Spectral analysis of $J 90$ jelly sample with permitted and nonpermitted colour standards. NP-1: nonpermitted Bromocresol purple; NP-2: nonpermitted Metanil yellow.

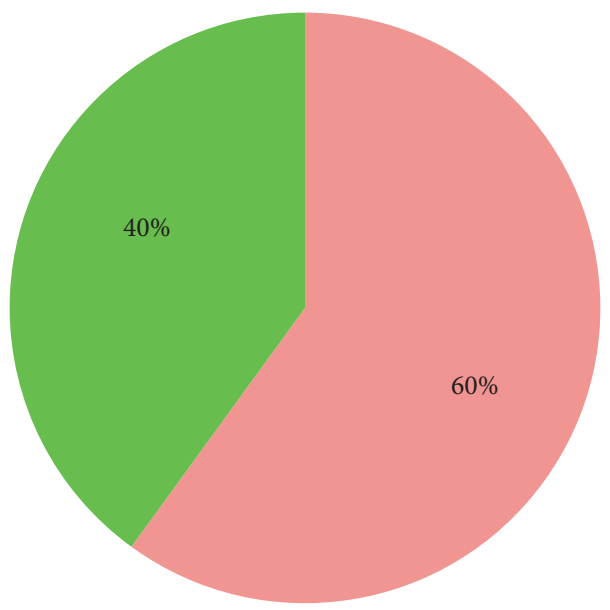

Label vialated samples

Label nonvialated samples

FIGURE 6: Label violation of beverages collected in Jaffna district as percentage.

TABLE 3: TLC analysis of beverage samples in Jaffna district.

\begin{tabular}{|c|c|c|c|c|c|}
\hline Sample number & $\begin{array}{c}\text { Physical } \\
\text { colour }\end{array}$ & $\begin{array}{l}\text { Collected place in } \\
\mathrm{MOH} \text { area }\end{array}$ & Colouring additive in label & Identified colours by TLC & $\begin{array}{c}\text { Label } \\
\text { violation }\end{array}$ \\
\hline $\begin{array}{l}\text { J111-wood apple } \\
\text { nectar }\end{array}$ & Brown & Sandilipay & $\begin{array}{l}\text { E122-Carmoisine, E140- } \\
\text { Chlorophyll }\end{array}$ & $\begin{array}{c}\text { Sunset yellow, Carmoisine, } \\
\text { Brilliant Blue }\end{array}$ & Yes \\
\hline $\begin{array}{l}\text { J112-orange } \\
\text { nectar }\end{array}$ & Orange & Sandilipay & $\begin{array}{l}\text { E122-Carmoisine, E140- } \\
\text { Chlorophyll }\end{array}$ & Sunset yellow & Yes \\
\hline J113-Nelli cordial & Green & Sandilipay & $\begin{array}{c}\text { E102-Tartrazine, E133-Brilliant } \\
\text { Blue }\end{array}$ & Tartrazine, Brilliant Blue & No \\
\hline J114-Nelli cordial & Green & Nallur & $\begin{array}{l}\text { Permitted colours (not mentioned } \\
\text { in the label) }\end{array}$ & Tartrazine, Brilliant Blue & Yes \\
\hline J115-Nelli cordial & Green & Jaffna & $\begin{array}{c}\text { E102-Tartrazine, E133-Brilliant } \\
\text { Blue }\end{array}$ & Tartrazine, Brilliant Blue & No \\
\hline J116-Nelli cordial & Green & Kopay & E102-Tartrazine & Tartrazine, Brilliant Blue & Yes \\
\hline
\end{tabular}


TABLE 3: Continued.

\begin{tabular}{lcccc}
\hline Sample number & $\begin{array}{c}\text { Physical } \\
\text { colour }\end{array}$ & $\begin{array}{c}\text { Collected place in } \\
\text { MOH area }\end{array}$ & Colouring additive in label & Identified colours by TLC \\
\hline J117-Nelli cordial & Green & Kopay & $\begin{array}{c}\text { E102-Tartrazine, E133-Brilliant } \\
\text { Blue }\end{array}$ & $\begin{array}{c}\text { Tartrazine, Brilliant Blue } \\
\text { E102-Tartrazine, E133-Brilliant } \\
\text { Bl18-Nelli cordial }\end{array}$ \\
$\begin{array}{l}\text { J119-Pineapple } \\
\text { cordial }\end{array}$ & Yellow & Sandilipay & $\begin{array}{c}\text { E122-Carmoisine, E140- } \\
\text { Chlorophyll }\end{array}$ & Tartrazine, Brilliant Blue \\
$\begin{array}{l}\text { J120-Nelli cordial } \\
\text { Light green }\end{array}$ & Sandilipay & $\begin{array}{c}\text { E122-Carmoisine, E140- } \\
\text { Chlorophyll }\end{array}$ & Tartrazine \\
\hline
\end{tabular}

Moreover, Figure 6 and Table 3 show $60 \%$ of beverages violated label requirement without mentioning the proper colour ingredients in the labels.

\section{Conclusions}

The study revealed excessive usage of permitted food colours in confectioneries and beverages of retail shops in Jaffna district. Some contained nonpermitted food colours and a textile dye "alizarin." Some beverage manufacturers violated the label requirement without including proper colour ingredients in the labels. Therefore, it is a dire need to create awareness in the society at different levels about the usage of synthetic food colours and toxic effects and health hazards of nonpermitted colours used in food items. Consequently, a systematic approach must be carried out within the country to establish rules and regulations to prevent malpractice of synthetic food colour adulteration and proper labelling of confectionaries and beverages and to control the permissible level of permitted synthetic colours to assure food safety and quality. This study also highlights the requirement of a governing authority to introduce global regulations on food safety.

\section{Data Availability}

The data used to support the findings of this study are available from the corresponding author upon request.

\section{Disclosure}

Part of the study was presented in the ICMA Post Graduate conference 2017, Faculty of Graduate Studies, University of Sri Jayewardenepura, Sri Lanka (53).

\section{Conflicts of Interest}

The authors declare that they have no conflicts of interest.

\section{Acknowledgments}

This study was supported by the Department of Botany and Instrument Center at Faculty of Applied Sciences, University of Sri Jayewardenepura (USJP), Sri Lanka, and Department of Nutrition, Medical Research Institute, Colombo-08, Sri Lanka. The authors would like to acknowledge all PHI (public health inspectors) officers, all $\mathrm{MOH}$ (Medical
Officers of Health) officers, senior PHI (SPHI) officer, and director of health in Jaffna, Northern Province, Sri Lanka, for their valuable contribution.

\section{References}

[1] S. P. Alves, D. M. Brum, É. C. Branco de Andrade, and A. D. Pereira Netto, "Determination of synthetic dyes in selected foodstuffs by high performance liquid chromatography with UV-DAD detection," Food Chemistry, vol. 107, no. 1, pp. 489-496, 2008.

[2] D. S. Yadav, S. Jaiswal, M. K. Mishra, and A. K. Gupta, "Analysis of non-permitted dyes in bakery and dairy products for forensic Consideration," International Journal of Development Research, vol. 6, pp. 8775-8779, 2016.

[3] K. Y. W. Lok, Y. W. Chung, I. F. F. Benzie, and J. Woo, "Synthetic colourings of some snack foods consumed by primary school children aged 8-9 years in Hong Kong," Food Additives and Contaminants: Part B, vol. 4, no. 3, pp. 162-167, 2011.

[4] J. N. Hathcock and J. I. Rader, "Aditivos, contaminantes e toxinas naturais de alimentos," in Tratado de Nutric_ao Moderna na Sau de e na Doenc_a, Editora Manole Ltda, Sao Paulo, Brazil, 9th edition, 2003.

[5] P. Rao, R. V. Bhat, R. V. Sudershan, and T. Prasanna Krishna, "Consumption of synthetic food colours during festivals in Hyderabad, India," British Food Journal, vol. 107, no. 5, pp. 276-284, 2005.

[6] N. Ashfaq and T. Masud, "Surveillance on artifical colours in different ready to eat foods," Pakistan Journal of Nutrition, vol. 1, no. 5, pp. 223-225, 2002.

[7] M. Rezaei, F. S. Abadi, Z. Sharifi et al., "Assessment of synthetic dyes in food stuffs produced in confectioneries and restaurants in Arak, Iran,” Thrita, vol. 3, no. 4, 2014.

[8] F. Farzianpour, G. J. Khaniki, M. Younesian, B. B. Ghahferkhi, M. Sadeghi, and S. Hosseini, "Evaluation of food color consumption and determining color type by thin layer chromatography," American Journal of Applied Sciences, vol. 10, no. 2, pp. 172-178, 2013.

[9] P. Rao and R. V. Sudershan, "Risk assessment of synthetic food colours: a case study in Hyderabad, India," International Journal of Food Safety, Nutrition and Public Health, vol. 1, no. 1, pp. 68-87, 2008.

[10] A. Downham and P. Collins, "Colouring our foods in the last and next millennium," International Journal of Food Science \& Technology, vol. 35, no. 1, pp. 5-22, 2000.

[11] R. Schuster and A. Gratzfeld-Hüsgen, Analysis of Synthetic Dyes in Food Samples by Capillary Zone Electrophoresis, HP Company, Palo Alto, CA, USA, 1995. 
[12] N. Zahra, Z. F. Alim-un-Nisa, I. Kalim, and K. Saeed, "Identification of synthetic food dyes in beverages by thin layer chromatography," Pakistan Journal of Food Sciences, vol. 25, no. 4, pp. 178-181, 2015.

[13] M. K. Purba, N. Agrawal, and S. K. Shukla, "Detection of nonpermitted food colors in edibles," Journal of Forensic Research, vol. S4, 2015.

[14] N. Saleem, Z. Nasreen Umar, and S. Ismat khan, "Survey on the use of synthetic Food Colors in Food Samples procured from different educational institutes of Karachi city," Journal of Tropical Life Science, vol. 3, no. 1, pp. 1-7, 2013.

[15] N. Bachalla, "Identification of synthetic food colors adulteration by paper chromatography and spectrophotometric methods," IAIM, vol. 3, no. 6, pp. 182-191, 2016.

[16] P. P. Nath, K. Sarkar, P. Tarafder, M. Mondal, K. Das, and G. Paul, "Practice of using metanil yellow as food colour to process food in unorganized sector of west bengal-a case study," International Food Research Journal, vol. 22, no. 4, pp. 1424-1428, 2015.

[17] A. Shinde and M. Shinde, "Adulteration of Food by Synthetic Colours and Safe Natural Colours," Search And Research, vol. 1, no. 1, pp. 21-23, 2013.

[18] K. S. Rowe and K. J. Rowe, "Synthetic food coloring and behavior: a dose response effect in a double-blind, placebocontrolled, repeated-measures study," The Journal of Pediatrics, vol. 125, no. 5, pp. 691-698, 1994.

[19] T. E. Tuormaa, "The adverse effects of food additives on health: a review of the literature with a special emphasis on childhood hyperactivity," Journal of Orthomolecular Medicine, vol. 9, no. 4, pp. 225-243, 1994.

[20] A. Das and A. Mukherjee, "Genotoxicity testing of the food colours amaranth and tartrazine," International Journal of Human Genetics, vol. 4, no. 4, pp. 277-280, 2004.

[21] R. L. Singh, S. K. Khanna, and G. B. Singh, "Acute and shortterm toxicity studies on orange II," Veterinary and Human Toxicology, vol. 29, no. 4, pp. 300-304, 1987.

[22] O. Prasad and P. B. Rastogi, "Effect of feeding a commonly used nonpermitted food colour Orange II on the haematological values of Mus musculus," Journal of Food Science and Technology, vol. 19, no. 4, pp. 150-153, 1982.

[23] P. R. Jonnalagadda, P. Rao, R. V. Bhat, and A. Nadamuni Naidu, "Type, extent and use of colours in ready-to-eat (RTE) foods prepared in the non-industrial sector - a case study from Hyderabad, India," International Journal of Food Science and Technology, vol. 39, no. 2, pp. 125-131, 2004.

[24] K. T. Chung, G. E. Fulk, and M. Egan, "Reduction of azo dyes by intestinal anaerobes," Applied and Environmental Microbiology, vol. 35, no. 3, pp. 558-562, 1978.

[25] J. G. P. Power, R. M. Barnes, W. N. C. Nash, and J. D. Robinson, "Lead poisoning in Gurkha soldiers in Hong Kong," BMJ, vol. 3, no. 5666, pp. 336-337, 1969.

[26] S. S. Chandro and T. Nagaraja, "A food poisoning outbreak with chemical dye-an investigation report," Medical Journal of Armed Forces India, vol. 43, no. 4, pp. 291-293, 1987.

[27] S. Anita, S. R. Bhatt, and S. M. Bhatt, "Food adulteration and practices in urban area of Varanasi," Food Science Research Journal, vol. 1, no. 2, pp. 183-195, 2010.

[28] S. M. N. Khalid, "Food labeling regulations in south asian association for regional cooperation (SAARC) countries: benefits, challenges and implications," Turkish Journal of Agriculture-Food Science and Technology, vol. 3, no. 4, pp. 196-203, 2014.

[29] Extraordinary Gazette, Food Act, No. 26 of 1980-Sri Lanka, Ministry of Health-Coloring Substances, 2011.
[30] Extraordinary Gazette, Food Act, No. 26 of 1980-Sri Lanka, Ministry of Health-Coloring Substances, 2006.

[31] Extraordinary Gazette, Food Act, No. 26 of 1980-Sri Lanka, Ministry of Health-Food Labeling Advertising, 2005.

[32] H. William, Official Methods of Analysis (AOAC) Internationals, AOAC International, Rockville, MD, USA, 18th edition, 2005.

[33] H. Choi, "Risk assessment of daily intakes of artificial colour additives in food commonly consumed in Korea," Journal of Food and Nutrition Research, vol. 51, no. 1, pp. 13-22, 2012.

[34] S. S. Lockey, "Hypersensitivity to tartrazine (FD\&C Yellow No. 5) and other dyes and additives present in foods and pharmaceutical products," Annals of Allergy, vol. 38, no. 3, pp. 206-210, 1977.

[35] C. Dees, M. Askari, S. Garrett, K. Gehrs, D. Henley, and C. M. Ardies, "Estrogenic and DNA-damaging activity of Red No. 3 in human breast cancer cells," Environmental Health Perspectives, vol. 105, no. suppl 3, pp. 625-632, 1997.

[36] V. Sasirekha, M. Umadevi, and V. Ramakrishnan, "Solvatochromic study of 1,2-dihydroxyanthraquinone in neat and binary solvent mixtures," Spectrochimica Acta Part A: Molecular and Biomolecular Spectroscopy, vol. 69, no. 1, pp. 148-155, 2008.

[37] P. Cysewski, T. Jeliński, M. Przybyłek, and A. Shyichuk, "Color prediction from first principle quantum chemistry computations: a case of alizarin dissolved in methanol," New Journal of Chemistry, vol. 36, no. 9, pp. 1836-1843, 2012.

[38] S. Say-Liang-Fat and J.-P. Cornard, "Al(III) complexation by alizarin studied by electronic spectroscopy and quantum chemical calculations," Polyhedron, vol. 30, no. 13, pp. 23262332, 2011.

[39] R. N. Rogers and A. Arnoldi, Scientific Method Applied to the Shroud of Turin, a Review, University of California, Oakland, CA, USA, 2002.

[40] R. W. Sabnis, Handbook of Biological Dyes and Stains: Synthesis and Industrial Applications, John Wiley \& Sons, Hoboken, NJ, USA, 2010.

[41] Dudley Chemical Corporation Specializing in Biological Stains, Dyes, Fine Chemicals, Indicators, and Reagents Availability of Custom Manufacturing, 2014, http://www. dudley-chem.com/catalog/Dudley_Catalog.pdf.

[42] G. K. M. Rajapaksha, M. A. J. Wansapala, and A. B. G. Silva, "Detection of synthetic colours in selected foods \& beverages available in Colombo district, Sri Lanka," International Journal of Science and Research, vol. 6, no. 5, pp. 801-808, 2017. 


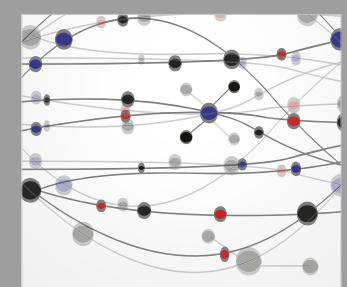

The Scientific World Journal
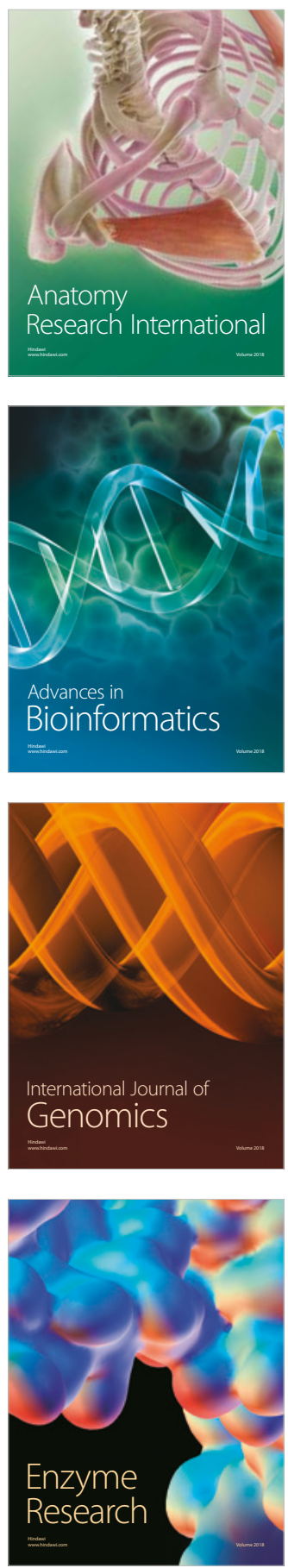
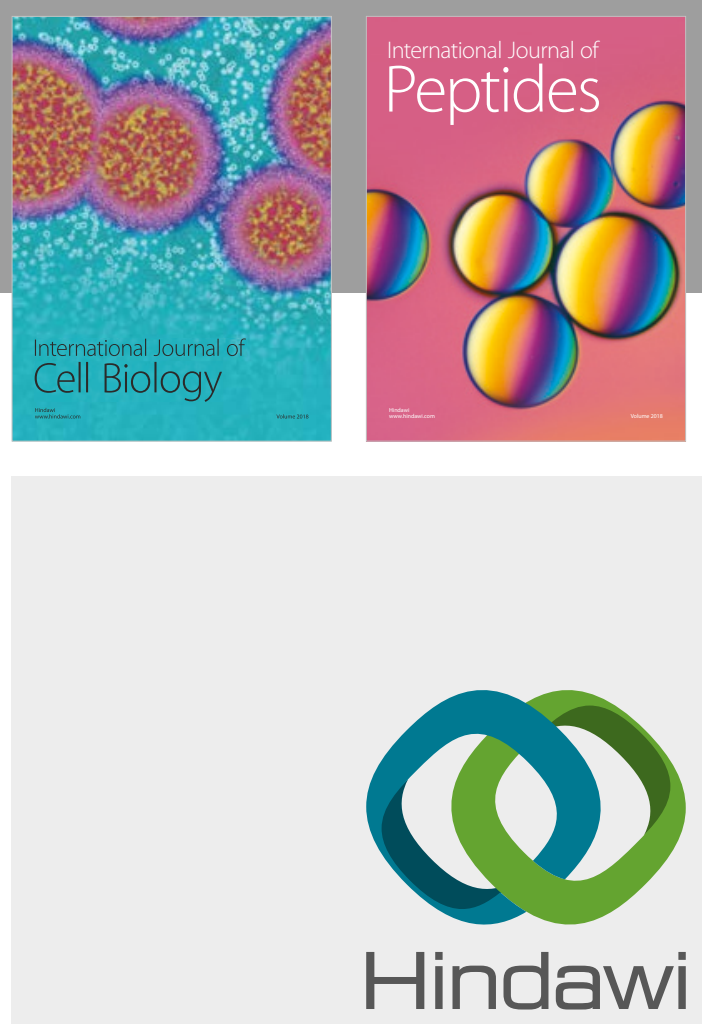

Submit your manuscripts at

www.hindawi.com
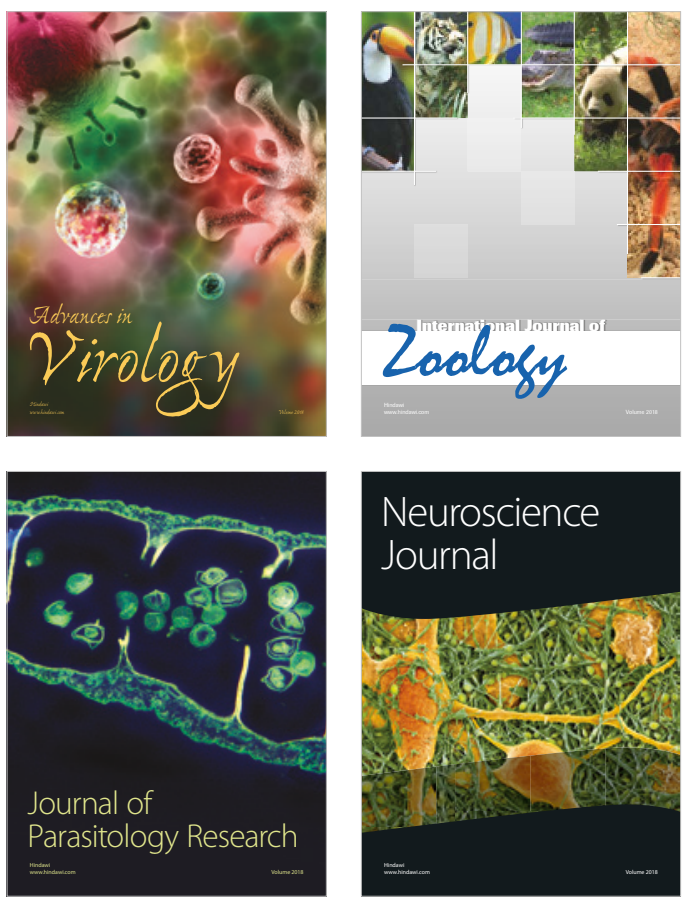
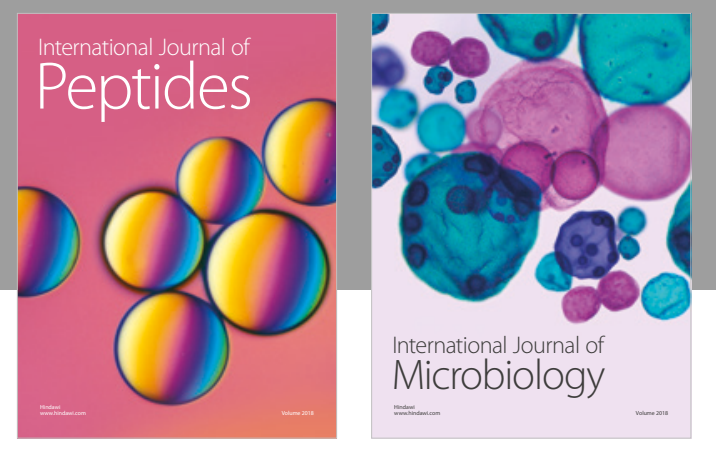

nternational Journal of Microbiology
Journal of
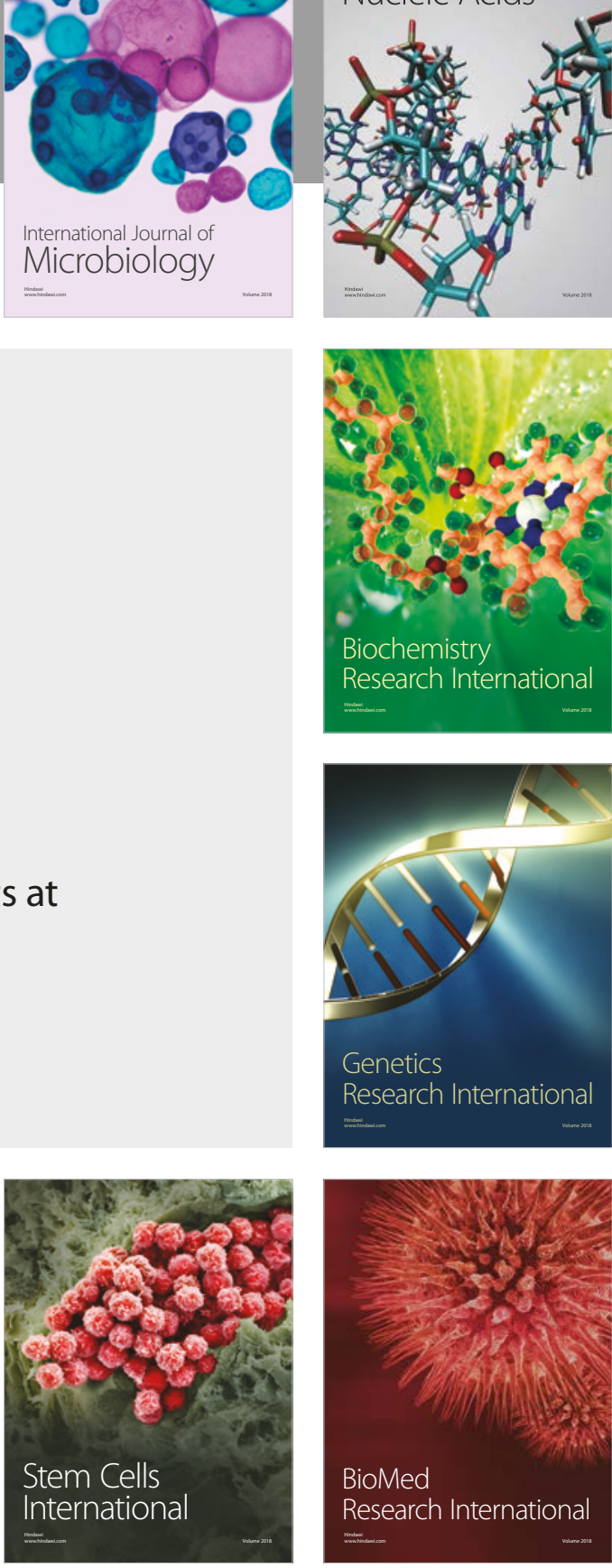
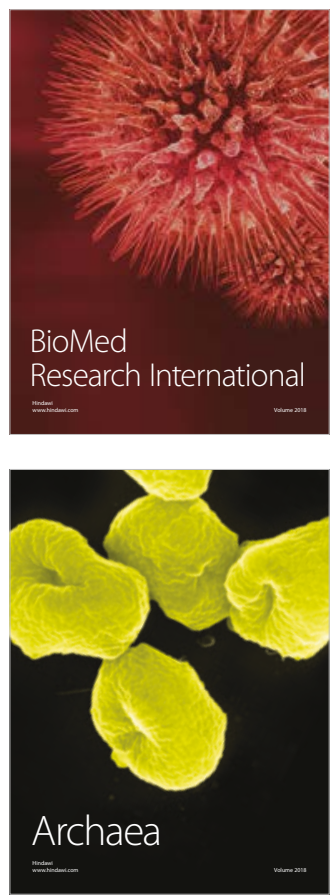